\title{
Belajar Bahasa Indonesia Dengan Model Pembelajaran Snowball Throwing Berbantuan Media Audio Visual
}

\author{
Risa Pramita Dewi ${ }^{1}$, I Gde Margunayasa ${ }^{2}$, I Made Suarjana ${ }^{3}$
}

1,2,3 Program Studi Pendidikan Guru Sekolah Dasar, Universitas Pendidikan Ganesha, Singaraja, Indonesia

\section{ART I C LE IN F O}

Article history:

Received July 09, 2021

Revised July 15, 2021

Accepted October 07, 2021

Available online October 25, 2021

Kata Kunci:

Hasil Belajar, Snowball

Throwing

Keywords:

Learning Outcomes, Snowball Throwing

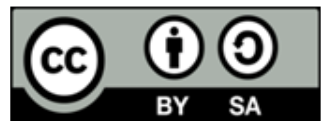

This is an open access article under the CC BY-SA license.

Copyright () 2021 by Author. Published by Universitas Pendidikan Ganesha.

\begin{abstract}
A B S T R A K
Kurangnya pemanfaatan media dan model-model pembelajaran membuat pembelajaran menjadi kurang efektif dan nantinya akan membuat hasil belajar siswa menurun. Oleh sebab itu, perlunya suatu penerapan model yang dapat mengatasi permalasahan tersebut contohnya adalah penerapan model pembelajaran snowball throwing berbantuan media audio visual. Penelitian ini bertujuan untuk menganalisis pengaruh model pembelajaran Snowball Throwing Berbantuan Media Audio Visual terhadap hasil belajar Bahasa Indonesia. Jenis penelitian yaitu eksperimen semu (quasy experiment). Populasi penelitian ini adalah 115 siswa. Sedangkan Sampel dalam penelitian ini sebanyak 2 kelas, yaitu kelas eksperimen dan kelas kontrol terdiri dari 43 orang. Pengumpulan data dilakukan dengan metode tes pilihan ganda dengan jumlah 25 soal. Data dianalisis menggunakan statistik deskriftif dan inferensial dengan uji-t. Berdasarkan analisis data dengan uji-t, diperoleh nilai $t(41)>t$ $(4,07)$. Hal ini menandakan bahwa terdapat pengaruh yang signifikan hasil belajar Bahasa Indonesia antara kelompok yang dibelajarkan dengan menggunakan Snowball Throwing berbantuan media audio visual dan kelompok siswa yang tidak dibelajarkan dengan Snowball Throwing berbantuan media audio visual pada siswa. Jadi, terdapat pengaruh secara efektif model Snowball Throwing berbantuan media audio visual dalam terhadap hasil belajar Bahasa Indonesia siswa. Implikasi dari penggunaan model ini dalam pembelajaran Bahasa Indonesia adalah membuat siswa menjadi lebih aktif dan mendapat pengalaman membangun sendiri pengetahuannya.
\end{abstract}

\section{A B S T R A C T}

The lack of use of media and learning models makes learning less effective and will make student learning outcomes decrease. Therefore, it is necessary to apply a model that can overcome these problems, for example, the application of the snowball throwing learning model assisted by audio-visual media. This study aims to analyze the effect of the Snowball Throwing Learning Model Assisted by Audio Visual Media on Indonesian language learning outcomes. The type of research is a quasi-experiment. The population of this study was 115 students. While the sample in this study were 2 classes, namely the experimental class and the control class consisting of 43 people. The data was collected using the multiple choice test method with a total of 25 questions. Data were analyzed using descriptive and inferential statistics with $t$-test. Based on data analysis by $t$-test, the value of $t(41)>t(4.07)$. This indicates that there is a significant effect on Indonesian language learning outcomes between the group that was taught using Snowball Throwing with the aid of audio-visual media and the group of students who were not taught by Snowball Throwing with the aid of audio-visual media. Based on this, it can be concluded that there is an effective effect of the Snowball Throwing model assisted by audio-visual media on students' Indonesian learning outcomes. The implication of using this model in learning Indonesian is to make students more active and gain experience in building their own knowledge.

\section{PENDAHULUAN}

Pendidikan merupakan faktor terpenting dalam kehidupan, karena pendidikan yang baik menghasilkan sumber daya yang berkualitas dan mampu bersaing. Abad 21 adalah abad pengetahuan sehingga sudah semestinya pendidikandiIndonesia lebih terbuka dan melangkah sejalan dengan tuntutan zaman. Hal ini semata agar bangsa Indonesia mampu beradaptasi tuntutan tersebut, namun dengan tetap berpegang teguh pada upaya pembentukan karakter siswa(Sudarsana, 2016; Widodo, 2016). Kompetensi yang menjadi fokus pengembangan 
dalam pendidikan abad 21 adalah yang berhubungan dengan kemampuan berliterasi siswa. Literasi yang dimaksudkan adalah kemampuan siswa dalam menganalisis bahkan menanggapi secara kritis informasi yang dibacanya (Hidayah, 2017). Hal sejalan juga dijelaskan bahwa pembelajaran yang dilaksanakan semestinya berorientasi pada upaya peningkatan keterampilan berpikir kritis, kreatif, inovatif, dan mampu menghubungkan ilmu pengetahuan dengan dunia nyata, serta menguasai teknologi informasi guna mempersiapkan siswa untuk siap bersaing dalam dunia kerja nantinya (Boso et al., 2021; Lavi et al., 2021; Risdianto, 2019; Rovers et al., 2018; Sung, 2017; Susilo \& Ramdiati, 2019). Hal ini juga berlaku dalam pembelajaran Bahasa Indonesia, yaitu proses pembelajaran Bahasa Indonesia hendaknya berorientasi pada pengembangan keterampilan berpikir tingkat tinggi. Muatan pembelajaran Bahasa Indonesia memiliki peranan penting dalam pendidikan karena muatan pembelajaran Bahasa Indonesia memiliki fungsi sebagai sarana berpikir logis dalam kehidupan sehari-hari (Handayani \& Subakti, 2021). Hal ini dikarenakan dalam pembelajaran bahasa Indonesia meliputi 4 komponen keterampilan, diantaranya yaitu; keterampilan menyimak, keterampilan berbicara, keterampilan membaca, dan keterampilan menulis(Ningrat \& Sumantri, 2019). Keterampilan tersebut dapat diwujudkan melalui proses pembelajaran yang inovatif. Proses pembelajaran yang demikian sangat bergantung pada kemampuan guru dalam memilih dan menerapkan strategi, model, metode, dan media pembelajaran (Harlina \& Wardarita, 2020). Penggunaan model dan media dalam pembelajaran akan memberikan kesan pembelajaran yang bermakna dan menarik (Ambarsari \& Hartono, 2017; Nilayanti et al., 2017). Lebih lanjut dijelaskan adanya media dalam proses pembelajaran akan membantu siswa dalam memahami materi yang bersifat abstrak dan dapat meningkatkan minat belajar siswa (Hadi, 2019; Hayati et al., 2017; Wahyuningtyas et al., 2020).

Namun kenyataan di lapangan menunjukan proses pembelajaran muatan Bahasa Indonesia bisa dikatakan masih belum optimal. Hal ini terbukti dari hasil survei oleh programme for international student assessment (PISA) tahun 2018 pada kategori kemampuan membaca, Indonesia berada di peringkat ke 74 dari 79 negara, sementara untuk penilaian kemampuan matematika dan kemampuan sains, Indonesia berada di peringkat ke 73 dan ke 71 dari ke 79 negara partisipan PISA (Hewi \& Shaleh, 2020; Yulianto et al., 2018). Jika dilihat khususnya kemampuan membaca siswa yang sangat berhubungan erat dengan pembelajaran Bahasa Indonesia menjadi masalah yang nyata untuk bangsa Indonesia kedepannya. Hasil observasi menunjukan bahwa penyebab rendahnya hasil belajar Bahasa Indonesia siswa adalah karena guru masih menggunakan model pembelajaran konvensional/ceramah yang pembelajarannya masih berpusat pada guru, sehingga menyebabkan siswa kurang antusias dalam mengikuti pembelajaran yang sedang berlangsung, dengan mengggunakan motode ceramah ini siswa menjadi cepat bosan dan sering mengantuk didalam kelas ketika menerima pelajaran, untuk itu guru perlu diberikan pengetahuan mengenai model pembelajaran yang dapat digunakan dalam proses belajar mengajar. Pada proses belajar mengajar guru masih belum menggunakan media pembelajaran, dalam menjelaskan materi guru hanya memberikan secara lisan tanpa memberikan gambaran/bayangan secara langsung kepada siswa, sehingga siswa tidak diberikan kesempatan untuk menggali informasi sendiri. Tugas yang diberikan cenderung bersifat individual, masih sangat jarang menggunakan kelompok belajar. Sehingga siswa menjadi lebih mementingkan diri sendiri dan tidak mau berdiskusi dengan teman. Beberapa penelitian juga menyebutkan permasalahan pembelajaran muatan Bahasa Indonesia yang hampir sama, yaitu guru belum menggunakan strategi, model, dan media pembelajaran yang sesuai dengan materi yang dibelajarkan (Anzar \& Mardhatillah, 2018; Oktaviani et al., 2019). Apabila permasalahan tersebut tidak segera diatasi, maka akan berpengaruh pada rendahnya hasil belajar muatan Bahasa Indonesia.

Mengacu pada permasalahan tersebut, maka dirasa sangat perlu melalukan inovasi dalam proses pembelajaran khususnya muatan Bahasa Indonesia. Alternatif yang dapat dilakukan adalah dengan menerapkan model pembelajaran. Salah satu model yang sesuai untuk digunakan adalah model pembelajaran snowball throwing. Model pembelajaran snowball throwing merupakan sebuah proses pembelajaran yang dilakukan dengan membentuk kelompok yang diwakili ketua kelompok untuk mendapat tugas dari guru kemudian masingmasing kelompok membuat pertanyaan yang ditulis dalam lembar kertas kerja yang dibentuk seperti bola lalu dilempar ke kelompok lain dan masing-masing kelompok menjawab pertanyaan dari bola yang diperoleh(Hujaemah et al., 2019; Lestari et al., 2017). Lebih lanjut dijelaskan bahwa model ini melatih kemampuan untuk bekerja sama dalam memecahkan permasalahan (Bera, 2020). Hasil beberapa penelitian sebelumnya menunjukan bahwa penggunaan model pembelajaran snowball throwing dalam pembelajaran berdampak positif terhadap hasil belajar siswa SD seperti: penggunaan model ini berpengaruh pada peningkatan hasil belajar PKn siswa(Bera, 2020); lebih lanjut penggunaan model ini juga memberikan pengaruh positif terhadap hasil belajar IPA siswa(Hujaemah et al., 2019; Sutiani et al., 2018). Model pembelajaran snowball throwing akan memberikan dampak yang optimal apabila dipadukan dengan media pembelajaran. Salah satu media pembelajaran yang dapat dipadukan dengan model pembelajaran ini adalah media audio visual. Pemanfaatan media audio visual dapat melatih fokus karena media ini mencakup media aditif (mendengar) dan sekaligus gambar (Limbong \& S., 2020; Sulfemi \& Mayasari, 2019). Selaian itu, pemanfaatan media audio visual juga dapat meningkatkan keterampilan komunikatif, kolaboratif, dan pemecahan masalah (Kwangmuang et al., 2021). Hasil penelitian penerapan model pembelajaran berbantuan video pembelajaran memiliki pengaruh yang signifikan terhadap hasil belajar siswa (Hadi, 2017; Kurniawan \& Kuswandi, 2018; Pramana \& Suarjana, 2018; 
Siswinarti, 2019; Dewi et al., 2019). Hal yang membedakan penelitian ini dengan penelitian sebelumnya adalah penggunaan model snowball throwing yang dipadukan dengan media audio visual pada pembelajaran muatan Bahasa Indonesia. Tujuan penelitian ini adalah untuk menganalisis pengaruh model Snowball Throwing berbantuan media audio visual dalam terhadap hasil belajar Bahasa Indonesia siswa kelas III SD. Lebih lanjut, penelitian ini dilakukan untuk menilai perbedaan antara hasil belajar Bahasa Indonesia pada siswa yang dibelajarkan dengan menggunakan model pembelajaran Snowball Throwing berbantuan media audio visual dan siswa yang diajarkan dengan menggunakan model pembelajaran konvensional pada siswa kelas III SD

\section{METODE}

Rancangan penelitian yang digunakan adalah non equivalent pretest-postest control group design. Berikut adalah Tabel 1. rancangan penelitian non equivalent pretest-postest control group design. Non equivalent pretest-postest control group design bertujuan untuk menyelidiki tingkat kesamaan antar kelompok dan skor pengetahuan awal berfungsi sebagai kovariat untuk melakukan kontrol secara sisternatis (Farell et al., 2021). Pada pelaksanaan penelitian, baik pre-test maupun, post-test sama-sama dilakukan pada kelas eksperimen dan kelas control. Populasi dalam penelitian ini adalah kelas III di SD Gugus III Tambora Kecamatan Melaya Kabupaten Jembrana dengan 115 siswa. Sedangkan pupulasi pada penelitian ini menggunakan teknik cluster random sampling. setelah dilakukan pengambilan pupulasi didapat 2 kelas yang menjadi kelas eksperimen dan kelas control berjumlah 43 orang siswa.

Tabel 1. Rancangan Eksperimen Non-equivalent Post-test Only Control Group Design

\begin{tabular}{ccc}
\hline Kelas & Treatment & Post-test \\
\hline E & $X$ & 01 \\
K & - & 02 \\
\hline
\end{tabular}

Data yang dikumpulkan dalam penelitian ini adalah data tentang hasil belajar siswa pada mata pelajaran Bahasa Indonesia. Metode pengumpulan data dalam penelitian ini adalah metode tes. Sesuai dengan metode yang digunakan, maka instrumen yang digunakan dalam penelitian ini adalah tes kognitif objektif tipe tes pilihan ganda dengan jumlah 25 soal. Tes hasil belajar adalah instrumen untuk mengukur tingkat penguasaan siswa setelah melakukan proses pembelajaran. Dalam penyusunan tes butir diperhitungkan dengan tingkat kesukaran dan kemampuan siswa. Adapun kisi-kisi dalam penelitian ini dapat disajikan dalam bentuk tabel 2.

Tabel 2. Kisi-Kisi Tes Hasil Belajar Bahasa Indonesia

\begin{tabular}{|c|c|c|c|c|c|}
\hline & SK & KD & Indikator & $\begin{array}{l}\text { Nomor } \\
\text { Soal }\end{array}$ & Jenjang \\
\hline \multirow[t]{5}{*}{8.} & $\begin{array}{l}\text { Mengungkapkan } \\
\text { pikiran, } \\
\text { perasaan, dan }\end{array}$ & $\begin{array}{l}\text { 8.1. } \\
\text { Menulis karangan } \\
\text { sederhana berdasarkan } \\
\text { gambar seri menggunakan }\end{array}$ & $\begin{array}{l}\text { Megurutkan gambar seri } \\
\text { dengan memperhatikan } \\
\text { ejaan. }\end{array}$ & $\begin{array}{c}4,10,13 \\
17\end{array}$ & $\mathrm{C} 3$ \\
\hline & $\begin{array}{l}\text { informasi dalam } \\
\text { karangan } \\
\text { sederhana dan } \\
\text { puisi }\end{array}$ & $\begin{array}{l}\text { pilihan kata dan kalimat } \\
\text { yang tepat dengan } \\
\text { meperhatikan ejaan, } \\
\text { kapital, dan tanda titik }\end{array}$ & $\begin{array}{l}\text { Mengubah kalimat yang tepat } \\
\text { berdasarkkan karangan }\end{array}$ & $\begin{array}{l}1,6,9 \\
11,19\end{array}$ & $\mathrm{C} 2$ \\
\hline & & $\begin{array}{l}\text { 8.2. Menulis puisi berdasarkan } \\
\text { gambar dengan pilihan }\end{array}$ & $\begin{array}{l}\text { Menulis karangan sederhana } \\
\text { berdasarkan gambar }\end{array}$ & $\begin{array}{l}2,5,14 \\
20\end{array}$ & $\mathrm{C} 1$ \\
\hline & & kata yang menarik & $\begin{array}{l}\text { Menyebutkan tanda baca } \\
\text { yang benar }\end{array}$ & $7,15,18$ & $\mathrm{C} 5$ \\
\hline & & & $\begin{array}{l}\text { Memilih kalimat sederhana } \\
\text { sesuai gambar }\end{array}$ & $\begin{array}{c}3,8,12 \\
16\end{array}$ & $\mathrm{C} 4, \mathrm{C} 6$ \\
\hline
\end{tabular}

Untuk soal objektif, setiap soal disertai dengan empat alternative jawaban yang dapat dipilih oleh siswa (alternatif a, b, c, dan d). Setiap item akan diberikan skor 1 bila siswa menjawab dengan benar (jawaban dicocokan dengan kunci jawaban) serta skor 0 untuk siswa yang menjawab salah. Skor setiap jawaban kemudian dijumlahkan dan jumlah tersebut merupakan skor variabel hasil belajar Bahasa Indonesia. Skor hasil belajar Bahasa Indonesia akan diambil dari 0-100. Skor 0 merupakan skor minimal ideal, serta 100 merupakan skor maksimal ideal tes hasil belajar Bahasa Indonesia. Instrumen yang telah disusun selanjutnya dilakukan tahap uji validitas. Uji validitas dilakukan untuk mengetahui tingkat kevalidan instrumen tersebut dengan menggunakanGregory.Setelah data terkumpul dengan menggunakan instrumen tersebut, selanjunya akan dilakukan analisis data dengan teknik analisis statistik deskriptif dan statistik inferensial. Analisis statistik 
deskriptif yang digunakan yaitu, skor rata-rata (mean) tiap-tiap variabel dikonversikan dengan menggunakan kriteria rata-rata ideal (Mi) dan standar deviasi ideal (SDi), serta untuk menentukan skala penilaian lima. Sedangkan uji prasyarat yang harus dipenuhi sebelum melakukan analisis data utama untuk menguji hipotesis penelitian yaitu uji normalitas sebaran data ditiap kelompok dan uji homogentitas varians antar kelompok.

\section{HASIL DAN PEMBAHASAN}

\section{Hasil}

Deskripsi data penelitian ini meliputi skor hasil post-test siswa sebagai akibat dari siswa yang dibelajarkan menggunakan Model pembelajaran Snowball throwingberbantuan media audio visualdan siswa yang tidak dibelajarkan Model pembelajaran Snowball throwing. Untuk mempermudah pemahaman, deskripsi data skor hasil post-test disajikan kedalam tabel 3. Berdasarkan Table 3 diatas, rata-rata skor post-test hasil belajar Bahasa Indonesia kelompok eksperimen adalah 75,1.Ini berarti hasil belajar kelompok eksperimen berada pada kategori sangat tinggi. Sedangkan rata-rata skor post-test hasil belajar Bahasa Indonesia kelompok kontrol adalah 70,7 Ini berarti hasil belajar kelompok kontrol berada pada kategori tinggi.

Tabel 3. Deskripsi Data Hasil Belajar Siswa

\begin{tabular}{ccc}
\hline Statistik Deskriptif & Kelompok Eksperimen & Kelompok Kontrol \\
\hline Mean & 71,5 & 70,7 \\
Median & 76,5 & 69,38 \\
Standar Deviasi & 5,1 & 5,07 \\
Variance & 25,9 & 25,8 \\
\hline
\end{tabular}

Untuk mengetahui pengauh yang signifikan model pembelajaran Snowball throwing berbantuan media audio visual. Sebelum uji hipotesis sebelumnya dilakukan pengujian prasayat terhadap sebaran data yang meliputi uji normalitas sebaran data dan uji homogenitas terhadap hasil belajar Bahasa Indonesia III.Uji normalitas data dilakukan dengan menggunakan menggunakan rumus Chi-Kuadrat. diperoleh nilai 5,37 pada taraf signifikansi 5\% dengan derajat kebebasan 5 dan diketahui $\chi^{2}$ tabel adalah 5,591, ini berarti bahwa $\chi^{2}$ hit $<\chi^{2}$ tab, maka data hasil post-test siswa kelompok eksperimen berdistribusi normal. Sedangkan Chi kuadrat data hasil post-test kelompk kontrol $\chi^{2}$ hitung adalah 2,67 pada taraf signifikansi $5 \%$ dengan derajat kebebasan 5 dan diketahui $\chi^{2}$ tab $=5,591$, ini berarti bahwa $\chi^{2}$ hit $<\chi^{2}$ tab maka data hasil post-test kelompok kontrol berdistribusi normal. Uji homogenitas varians dilakukan untuk meyakinkan bahwa perbedaan benar-benar berasal dari perbedaan antar kelompok, bukan berasal dari perbedaan yang terjadi di dalam kelompok. Pengujian homogenitas varians dalam penelitian ini dilakukan dengan menggunakan uji Levene's Test for Equality of Variances. Diperoleh nilai Sig sebesar 0,395 untuk hasil belajar Bahasa Indonesia siswa. Nilai tersebut lebih besar dari 0,05. Hal ini menunjukkan varians skor kelompok adalah homogen. Dengan kata lain, kelompok data berasal dari sampel yang homogen. Kriteria pengujian hipotesis nol $\left(\mathrm{H}_{0}\right)$ ditolak apabila angka signifikansi yang diperoleh kurang dari 0,05. Hasil analisis uji $t$ diperoleh nilai $F_{\text {hitung }}=41$ dan $F_{\text {tabel }}=4,07$. Ini berarti $F_{\text {hitung }}>F_{\text {tabel }}$ $(41>4,07)$. Itu berarti pula bahwa hipotesis nol yang menyatakan tidak terdapat perbedaan hasil belajar Bahasa Indonesia siswa yang mengikuti model pembelajaran Snowballthrowing berbantuan media audio visual dengan siswa yang mengikuti pembelajaran konvensional, ditolak.

\section{Pembahasan}

Hasil penelitian yang tetah dilakukan adalah terdapat pengaruh model Snowballthrowing berbantuan media audio visual terhadap hasil belajar Bahasa Indonesia siswa kelas III. Pengaruh tersebut terlihat dari adanya perbedaan antara rata-rata skor hasil belajar Bahasa Indonesia siswa kelompok eksperimen dan kelompok kontrol. Perbedaan tersebut disebabkan model pembelajaran Snowball throwing berbantuan media audio visual pembelajaran adalah model pembelajaran yang melibatkan kelompok kecil untuk bekerja sama menyelesaikan permasalahan dengan bantuan konsep-konsep yang terhubung satu sama lain agar dapat membangun pengetahuan sendiri dalam kelompok. Membangun pengetahuan sendiri didukung dengan siswa lebih aktif saat proses pembelajaran dan aktif diskusi (S. P. Dewi et al., 2020; Diyantari et al., 2020; Oktaviani et al., 2019). Selain itu, Perbedaan yang signifikan antara siswa yang mengikuti pembelajaran Snowball Throwing berbantuan media audio visual dan siswa yang mengikuti pembelajaran konvensional disebabkan karena perbedaan perlakuan pada langkah-langkah pembelajaran dan proses penyampaian materi. Faktor yang mendukung keberhasilan seseorang pada penelitian ini yaitu model pembelajaran.

Penggunaan model Snowball Throwing berbantuan media audio visual dapat meningkatkan siswa dalam belajarh (Cahyadi et al., 2017; Dewi et al., 2017; Sari et al., 2020). Selain itu dengan penerapan model model Snowball Throwing berbantuan media audio visual siswa juga berperan katif dalam proses pembelajaran 
sehingga siswa yang dibelajarkan dengan model Snowball Throwing berbantuan media audio visual dapat memupuk rasa ingin tahu dan dapat menemukan pengetahuan sendiri di dalam proses pembelajaran. sehingga nantinya akan berpengaruh terhadap hasil belajar siswa itu sendiri. Selain itu, Model pembelajaran kooperatif tipe Snowball Throwing dapat menigkatkan aktivitas dan kreatifitas siswa, melatih siswa belajar mandiri dalam pengetahuan berdasarkan diskusi, mengembangkan kemampuan berpikir siswa dalam mendiskusikan dan meyelesaikan tugas belajar, mengembangkan kemampuan mengemukakan pendapat, meningkatkan kemampuan menjelaskan kembali materi yang diperoleh berdasarkan diskusi, dan meningkatkan hasil belajar siswa(Efiyanti et al., 2019). Snowball throwing merupakan model pembelajaran yang membagi murid dalam beberapa kelompok. Satu kelompok dapat terdiri dari 5 hingga 7 siswa (Kusumaningrum \& Setyawati, 2019). Model pembelajaran kooperatif tipe Snowball Trhowing adalah model pembelajaran yang mengaktifkan siswa secara keseluruhan karena pelajaran dibuat seperti permainan sehingga siswa lebih aktif dan menyenangkan dalam proses belajar mengajar (Nurhaedah \& Amran, 2017). Snowball throwing adalah salah satu model pembelajaran kooperatif dimana terdapat kerjasama anatar kelompok dan saling ketergantungan antar siswa (Putra et al., 2017). Pembelajaran dengan menggunakan Snowball Throwing dapat menciptakan rasa kebersamaan dalam kelompok baik antar anggota kelompok maupun dengan anggotakelompok lain (Oktaviani et al., 2019).

Selain itu, model Snowball throwing berbantuan media audio visual dapat meningktakan hasil belajar dikarenakan model ini dapat membuat siswa antusias dalam mengikuti pembelajran serata dapat mendengarkan pembelajran dengan baik. Selain itu dengan penerapan model ini seluruh siswa juga aktif dalam mengikuti proses pembelajaran yang menggunakan model ini dan siswa juga dapat mendengar menggunakan berbagai indra yang dimiliki oleh setiap individu. Dengan demikian jika siswa menggunakan seluruh alat indranya dalam proses pembelajaran tentunya siswa tersebut akan mengingat lama materi yang disampaikan oleh gurunya.Selain itu,Snowball throwing dapat membangkitkan keberanian siswa dalam mengemukakan pertanyaan kepada teman yanglain maupun guru (Fitriani et al., 2019). Snowball Throwing adalah kegiatan pembelajaran yang disertaidengan permainan pelemparan kertas berisi pertanyaan yang dibentuk menyerupai bola salju, sehingga kegiatan belajar mengajar menjadi jauh lebih menyenangkan (Gusti, 2019; Sartono, 2017). Snowball throwing siswa dituntut untuk dapat menguasai materi, melatih siswa berfikir kreatif dan belajar bertanggung jawab dalam menjalankan tugas.Snowball Throwing juga dapat menigkatkanaktivitas dan kreatifitas siswa, melatih siswa belajar mandiri dalam pengetahuan berdasarkan diskusi,mengembangkan kemampuan (Rosidah, 2017). Metode snowball throwing menstimulus siswa untuk menyelesaikan masalah, komunikasi, penalaran, dan kepercayaan diri (Kurniawan, 2017). Jabaran tentang model snowball throwing memberikan suasana pembelajaran yang lebih menarik dimana siswa aktif belajar sambil bermain dengan pertanyaan yang dikemas semenarik mungkin.

Adapun kelebihan dari model Snowball Throwing adalah menjadikan siswa aktif dalam pembelajaran, Aktivitas belajar menjadi joyfull atau penuh dengan kegembiraan karena siswa seperti bermain lempar bola salju, kemampuan berpikir kritis siswa dilatih melalui instruksi membuat dan menjawab pertanyaan, mempersiapkan siswa dengan segala situasi karena siswa tidak dapat menerka pertanyaan yang dibuat temannya, melatih kepercayaan diri siswa dalam mengemukakan pendapatnya di depan umum, pembelajaran menjadi efektif dan komunikatif sehingga tercapainya tujuan pembelajaran secara optimal, aspek kognitif, afektif, dan psikomotor siswa dapat tercapai (Asmariati, 2020; Indriani, 2017; Shoimin, 2017). Implikasi pada penelitian ini adalah Penggunaan model Pembelajaran Snowball throwing berbantuan audio visual dalam pembelajaran menimbulkan kerjasama yang membangun pengetahuan siswa sendiri sehingga proses pembelajaran menjadi terpusat pada siswa. Jadi, selama proses pembelajaran siswa tidak hanya mengandalkan informasi yang diperoleh dari guru saja, melainkan siswa dituntut untuk menjadi individu yang aktif dalam menggali pengetahuannya sendiri serta menyiapkan diri dengan materi agar dapat memecahkan masalahmasalah dan pertanyaan-pertanyaan yang diberikan oleh guru. Hasil penelitian ini dapat dijadikan masukan bagi guru untuk memilih model pembelajaran yang bervariasi dalam mengajar agar mampu menguah suasana pembelajaran di kelas menjadi lebih menyenangkan sehingga siswa tidak merasa jenuh ataupun bosan dalam mengikutin pembelajaran. Model Pembelajaran Snowball throwing berbantuan audio visual dapat diaplikasikan dalam pembelajaran Bahasa Indonesia di sekolah dasar sebagai upaya guru untuk pencapai hasil belajar siswa secara maksimal pada mata pelajaran Bahasa Indonesia, dan dapat dijadikan masukan bagi Kepala Sekolah dalam upaya peningkatan kualitas pendidikan dan pembelajaran di sekolah dengan mensosialisasikan penerapan suatu model pembelajaran yang inovatif dalam pembelajaran.

\section{SIMPULAN}

Terdapat pengaruh secara efektif model Snowball Throwing berbantuan media audio visual dalam terhadap hasil belajar Bahasa Indonesia. Model Pembelajaran Snowball throwing berbantuan audio visual dapat diaplikasikan dalam pembelajaran Bahasa Indonesia di sekolah dasar sebagai upaya guru untuk pencapai hasil belajar siswa secara maksimal pada mata pelajaran Bahasa Indonesia, dan dapat dijadikan masukan bagi Kepala 
Sekolah dalam upaya peningkatan kualitas pendidikan dan pembelajaran di sekolah dengan mensosialisasikan penerapan suatu model pembelajaran yang inovatif dalam pembelajaran.

\section{DAFTAR PUSTAKA}

Ambarsari, D. W., \& Hartono, B. (2017). Pengembangan Media Pop Culture UP Rumah Adat Jawa untuk Pembelajaran Menyusun Teks Deskripsi pada Peserta Didik SMP Kelas VII. Jurnal Semantik, 6(2), 1-10. http://e-journal.stkipsiliwangi.ac.id/index.php/semantik/article/view/489.

Anzar, S. F., \& Mardhatillah, M. (2018). Analisis Kesulitan Belajar Siswa Pada Pembelajaran Bahasa Indonesia di Kelas V SD Negeri 20 Meulaboh Kabupaten Aceh Barat Tahun Ajaran 2015/2016. Bina Gogik: Jurnal Ilmiah Pendidikan Guru Sekolah https://ejournal.stkipbbm.ac.id/index.php/pgsd/article/view/25.

Asmariati, A. (2020). Penerapan Model Pembelajaran Kooperatif Tipe Snowball Throwing Untuk Meningkatkan Aktivitas Dan Hasil Belajar Siswa. Urnal Kinerja Kependidikan (JKK), 2(4), 722-745. https://doi.org/http://ojs.serambimekkah.ac.id/JKK/article/view/2455.

Bera, L. (2020). Pengaruh Model Snowball Throwing Terhadap Hasil Belajar Siswa Kelas V Pada Mata Pelajaran PKn Di SD Inpres Xx Solot. Equilibrium: Jurnal Penelitian Pendidikan Dan Ekonomi, 17(2), 61-68. https://journal.uniku.ac.id/index.php/Equilibrium/article/viewFile/2826/1936.

Boso, C. M., van der Merwe, A. S., \& Gross, J. (2021). Students' and educators' experiences with instructional activities towards critical thinking skills acquisition in a nursing school. International Journal of Africa Nursing Sciences, 14. https://www.sciencedirect.com/science/article/pii/S2214139121000160.

Cahyadi, I. G., Renda, N. T., \& Suartama, I. K. (2017). Pengaruh Model Pembelajaran Kooperatif Tipe Snowball Throwing Berbantuan Media Video Clip Terhadap Hasil Belajar IPA. Mimbar PGSD Undiksha, 5(2). https://ejournal.undiksha.ac.id/index.php/JJPGSD/article/view/10773.

Dewi, N. P. K. R., Ngurah Suadnyana, I., \& Abadi, I. G. S. (2017). Pengaruh Model Pembelajaran Snowball Throwing Berbantuan Media Audiovisual Terhadap Penguasaan Kompetensi Pengetahuan IPA. Journal of Education Technology, 1(3), 191-197. https://ejournal.undiksha.ac.id/index.php/JET/article/view/12504.

Dewi, N. W. S. K., Parmiti, D. P., \& I Gusti Ngurah Japa. (2019). Pengaruh Model Pembelajaran Probing Prompting Berbantuan Media Video Terhadap Hasil Belajar IPA. Indonesian Journal of Educational Research and Review, 2(2), 229-239. https://ejournal.undiksha.ac.id/index.php/IJERR/article/view/17631.

Dewi, S. P., Ardana, I. K., \& Asri, I. G. A. A. S. (2020). Model Pembelajaran Snowball Throwing Berbantuan Media Audio Visual Terhadap Kompetensi Pengetahuan IPA. Jurnal Penelitian Dan Pengembangan Pendidikan, 4(2), 296-305. https://ejournal.undiksha.ac.id/index.php/JJL/article/view/26435/15968.

Diyantari, I. A. K. D., Wiyasa, N., \& Manuaba, S. (2020). Model Snowball Throwing Berbantuan Media Pop Up Book Berpengaruh Terhadap Kompetensi Pengetahuan IPA. Jurnal Ilmiah Pendidikan Profesi Guru, 3(1), 9-21. http://dx.doi.org/10.23887/jippg.v3i1.26973.

Efiyanti, N. P., Suarni, N. K., \& Parmiti, D. P. (2019). Pengaruh Model Pembelajaran Snowball Throwing Berbasis Penilaian Proyek Terhadap Hasil Belajar IPS. Jurnal Ilmiah Pendidikan Profesi Guru, 2(2), 119-129. https://ejournal.undiksha.ac.id/index.php/JIPPG/article/view/19174.

Farell, G., Ambiyar, A., Simatupang, W., Giatman, M., \& Syahril, S. (2021). Analisis Efektivitas Pembelajaran Daring Pada SMK Dengan Metode Asynchronous dan Synchronous. Edukatif: Jurnal Ilmu Pendidikan, 3(4), 11851190. https://www.edukatif.org/index.php/edukatif/article/view/521.

Fitriani, I. N., Al-Ghozali, M. D. H., \& Ashoumi, H. (2019). Efektivitas Metode Pembelajaran Snowball Throwing Pada Mata Pelajaran Al-Qur'an Hadist Untuk Meningkatkan Minat Belajar Siswa Kelas XI di MAN 1 $\begin{array}{llll}\text { Jombang. } \quad \text { At-Tuhfah: Jurnal } & \text { Studi }\end{array}$ https://journal.unnes.ac.id/nju/index.php/JPTM/article/download/9143/5957.

Gusti, A. M. A. P. (2019). Pengaruh Metode Pembelajaran E-Learning dan Snowball Throwing Terhadap Prestasi Belajar Mahasiswa di Kelas Kalkulus Institut Teknologi dan Bisnis Stikom Bali. Square: Journal of $\begin{array}{lllll}\text { Mathematics and } \quad \text { Mathematics } & \text { Education, } & 103 \text {, }\end{array}$ https://journal.walisongo.ac.id/index.php/square/article/view/4265.

Hadi, S. (2019). Problematik Pendidikan Bahasa Indonesia Kajian Pembelajaran Bahasa Indonesia pada Sekolah Dasar. Jurnal Pendidikan: Riset Dan Konseptual, 3(4), 74-78. http://journal.unublitar.ac.id/pendidikan/index.php/Riset_Konseptual/article/view/108.

Hadi, Sofyan. (2017). Efektivitas Penggunaan Video Sebagai Media Pembelajaran Untuk Siswa Sekolah Dasar. $\begin{array}{lllll}\text { Transformasi Pendidikan } & \text { Abad }\end{array}$ http://pasca.um.ac.id/conferences/index.php/sntepnpdas/article/view/849.

Handayani, E. S., \& Subakti, H. (2021). Pengaruh Disiplin Belajar terhadap Hasil Belajar Bahasa Indonesia di Sekolah Dasar. Jurnal Basicedu, 5(1), 151-164. http://jbasic.org/index.php/basicedu/article/view/633.

Harlina, H., \& Wardarita, R. (2020). Peran Pembelajaran Bahasa dalam Pembentukan Karakter Siswa Sekolah 
Dasar. Jurnal Bindo Sastra, 4(1), 63-68. https://jurnal.umpalembang.ac.id/bisastra/article/view/2332/1848.

Hayati, Najmi, \& Harianto, F. (2017). Hubungan Penggunaan Media Pembelajaran Audio Visual dengan Minat Peserta Didik Pada Pembelajaran Pendidikan Agama Islam di SMAN 1 Bangkinang Kota. Jurnal Agama Dan Ilmu Pengetahuan, 14(2). https://journal.uir.ac.id/index.php/alhikmah/article/view/1027.

Hewi, L., \& Shaleh, M. (2020). Refleksi Hasil PISA (The Programme For International Student Assesment): Upaya Perbaikan Bertumpu Pada Pendidikan Anak Usia Dini. Jurnal Golden Age, 4(01), 30-41. https://ejournal.hamzanwadi.ac.id/index.php/jga/article/view/2018/1275.

Hidayah, L. (2017). Implementasi budaya literasi di sekolah dasar melalui optimalisasi perpustakaan: Studi kasus di Sekolah Dasar Negeri di Surabaya. JU-Ke (Jurnal Ketahanan Pangan), 1(2), 48-58. http://riset.unisma.ac.id/index.php/JU-ke/article/view/791/765.

Hujaemah, E., Saefurrohman, A., \& Juhji, J. (2019). Pengaruh penerapan model snowball throwing terhadap hasil belajar ipa di sekolah dasar. Muallimuna: Jurnal Madrasah Ibtidaiyah, 5(1), 23-32. https://ojs.uniskabjm.ac.id/index.php/jurnalmuallimuna/article/view/2203.

Indriani, N. (2017). Meningkatkan Percaya diri siswa melalui model Snowball Throwing dalam pembelajaran IPA pada siswa kelas IV di SD Negeri 111/1 Muara Bulian. Jurnal Meningkatkan Percaya Diri Siswa Melalui Model Snowball Throwing Dalam Pembelajaran Ipa Pada Siswa Kelas Iv Di Sd Negeri 111/1 Muara Bulian. https://repository.unja.ac.id/Id/Eprint/1339.

Kurniawan, D., Kuswandi, D., \& Husna, A. (2018). Pengembangan media video pembelajaran pada mata pelajaran IPA tentang sifat dan perubahan wujud benda kelas IV SDN Merjosari 5 Malang. JINOTEP (Jurnal Inovasi Dan Teknologi Pembelajaran) Kajian Dan Riset Dalam Teknologi Pembelajaran, 4(2), 119-125. https://ejournal.undiksha.ac.id/index.php/JISD/article/view/15487.

Kurniawan, M. U. (2017). Perbedaan Hasil Pembelajaran Akuntansi Menggunakan Metode Snowball Throwing Dan Metode Konvensional Pada Siswa Kelas XI IPS SMAN Arjasa. Assets: Jurnal Akuntansi Dan Pendidikan, 6(1), 42. http://e-journal.unipma.ac.id/index.php/assets/article/view/1292.

Kusumaningrum, S., \& Setyawati, I. G. (2019). Penerapan Metode Snowball Throwing Dalam Pembelajaran Baahasa Inggris Untuk Meningkatkan Penguasaan Kosa Kata Dan Kemampuan Psikomotorik Siswa SD Islam Terpadu Kota Sorong. Jurnal Pendidikan, 7(1), 21-29. https://unimuda.ejournal.id/jurnalpendidikan/article/view/207.

Kwangmuang, P., Jarutkamolpong, S., Sangboonraung, W., \& Daungtod, S. (2021). The development of learning innovation to enhance higher order thinking skills for students in Thailand junior high schools. Heliyon. https://doi.org/10.1016/j.heliyon.2021.e07309.

Lavi, R., Tal, M., \& Dori, Y. J. (2021). Perceptions of STEM alumni and students on developing 21st century skills through methods of teaching and learning. Studies in Educational Evaluation, 70, 1-11. https://doi.org/10.1016/j.stueduc.2021.101002.

Lestari, N. M. D., Suniasih, N. W., \& Darsana, I. W. (2017). Pengaruh Model Pembelajaran Snowball Throwing Berbasis Lagu-Lagu Anak Terhadap Kompetensi Pengetahuan PKN. Journal of Education Technology, 1(3), 163-168. https://ejournal.undiksha.ac.id/index.php/JET/article/view/12500.

Limbong, T., \& S., J. (2020). Media dan Multimedia Pembelajaran: Teori \& Praktik. Yayasan Kita Menulis.

Nilayanti, P. M., Putra, I. K. A., \& Suadnyana, I. N. (2017). Pengaruh Model Pembelajaran Kooperatif Tipe Number Head Together Berbantuan Media Konkret Terhadap Kompetensi Pengetahuan Ipa Siswa Kelas IV SD Gugus Kompyang Sujana Denpasar Utara. Mimbar PGSD, 5(3), 1-9. https://ejournal.undiksha.ac.id/index.php/JJPGSD/article/view/10781.

Ningrat, S. P., \& Sumantri, M. (2019). Kontribusi Gaya Belajar Dan Motivasi Belajar Terhadap Hasil Belajar Bahasa Indonesia Siswa Kelas V SD. JISD 2(3), 145-152. http://dx.doi.org/10.23887/jisd.v2i3.16140.

Nurhaedah, A., \& Amran, M. (2017). Penerapan Model Pembelajaran Kooperatif Tipe Snowball Throwing Untuk Meningkatkan Hasil Belajar Siswa Pada Mata Pelajaran IPS Kelas V SDN Mapala Kota Makassar. JIKAP PGSD: Jurnal Ilmiah Ilmu Kependidikan, 1(1), 11-22. https://ojs.unm.ac.id/JIKAP/article/view/5041.

Oktaviani, M. D. S., Suwatra, I. W., \& Murda, N. (2019). Pengaruh Model Pembelajaran Snowball Throwing Berbantuan Media Audiovisual terhadap Hasil Belajar Bahasa Indonesia. Jurnal Ilmiah Sekolah Dasar, 3(1), 89-97. https://ejournal.undiksha.ac.id/index.php/JISD/article/view/17662.

Pramana, I. P. Y., \& Suarjana, I. M. (2019). Pengaruh Model Pembelajaran Time Token Berbantuan Media Video Terhadap Hasil Belajar Ipa Kelas V SD. Journal of Education Technology, 2(4), 137. https://doi.org/10.23887/jet.v2i4.16425.

Putra, I. K. S., Sudana, D. N., \& Tastra, I. D. K. (2017). Pengaruh Model Pembelajaran Kooperatif Tipe Snowball Throwing Berbantuan Media Power Point Terhadap Hasil Belajar IPA. Mimbar PGSD Undiksha, 5(2). https://ejournal.undiksha.ac.id/index.php/JJPGSD/article/view/10769.

Risdianto, E. (2019). Analisis pendidikan indonesia di era revolusi industri 4.0. Bengkulu. Universitas Bengkulu. https://www.researchgate.net.

Rosidah, A. (2017). Penerapan Model Pembelajaran Kooperatif Snowball Throwing Untuk Meningkatkan Hasil 
Belajar Siswa Pada Pembelajaran IPS. Jurnal Cakrawala Pendas, 3(2). http://jurnal.unma.ac.id/index.php/CP/article/view/593.

Rovers, S. F. E., Clarebout, G., Savelberg, H. H. C. M., \& van Merriënboer, J. J. G. (2018). Improving student expectations of learning in a problem-based environment. Computers in Human Behavior, 87, 416-423. https://doi.org/10.1016/j.chb.2018.02.016.

Sari, N. L. G. L. C., Wiyasa, I. K. N., \& Negara, I. G. A. O. (2020). Model Pembelajaran Snowball Throwing Berbantuan Lagu Daerah Terhadap Kompetensi Pengetahuan IPA Siswa Kelas IV. Jurnal Adat Dan Budaya, 2(2). https://ejournal.undiksha.ac.id/index.php/JABI/index

Sartono, L. N. (2017). Pengaruh Metode Snow Ball Throwing Terhadap Hasil Belajar Matematika Siswa SD. Elementary School Education Journal, 3(1), 93-103. http://103.114.35.30/index.php/pgsd/article/viewFile/1400/1183.

Shoimin, A. (2017). 68 Model Pembelajaran Inovatif Dalam Kurikulum 2013 (KR Rose (Ed.); Pertama). ArRuzz Media.

Siswinarti, P. R. (2019). Pengaruh Model Pembelajaran Value Clarification Technique Bermediakan Video Terhadap Hasil Belajar Pkn. Jurnal Ilmiah Pendidikan Profesi Guru, 2(1), 41-49. https://ejournal.undiksha.ac.id/index.php/JIPPG/article/view/18084.

Sudarsana, I. K. (2016). Pemikiran tokoh pendidikan dalam buku lifelong learning: policies, practices, and programs (Perspektif Peningkatan Mutu Pendidikan di Indonesia). Jurnal Penjaminan Mutu, 2(2), 44-53. http://www.ejournal.ihdn.ac.id/index.php/JPM/article/view/71/80.

Sulfemi, W. B., \& Mayasari, N. (2019). Peranan Model Pembelajaran Value Clarification Technique Berbantuan Media Audio Visual untuk Meningkatkan Hasil Belajar IPS. Jurnal Pendidikan, 20(1), 53-68. https://doi.org/10.33830/jp.v20i1.235.2019.

Sung, E. (2017). The influence of visualization tendency on problem-solving ability and learning achievement of primary school students in South Korea. Thinking Skills and Creativity, 26, 168-175. https://doi.org/doi:10.1016/j.tsc.2017.10.

Susilo, S. V., \& Ramdiati, T. (2019). Penerapan Model Multiliterasi Untuk Meningkatkan Keterampilan Menulis Karangan Persuasi Pada Mata Pelajaran Bahasa Indonesia Di Sekolah Dasar. Jurnal Cakrawala Pendas, 5(1). http://jurnal.unma.ac.id/index.php/CP/article/view/1199.

Sutiani, K., Suarni, N. K., \& Dibia, I. K. (2018). Pengaruh model pembelajaran snowball throwing berbasis penilaian kinerja terhadap hasil belajar IPA. International Journal of Elementary Education, 2(3), 173182. https://ejournal.undiksha.ac.id/index.php/IJEE/article/view/15956.

Wahyuningtyas, Rizki, \& Sulasmono, B. S. (2020). Pentingnya Media Dalam Pembelajaran Guna Meningkatkan Hasil Belajar di Sekolah Dasar. Jurnal Basicedu, 2(1). https://doi.org/10.31004/edukatif.v2i1.77.

Widodo, H. (2016). Potret pendidikan di Indonesia dan kesiapannya dalam menghadapi masyarakat ekonomi Asia (MEA). Cendekia: Jurnal Kependidikan Dan Kemasyarakatan, 13(2), 293-308. http://jurnal.iainponorogo.ac.id/index.php/cendekia/article/view/250.

Yulianto, B., Jannah, F., Nurhidayah, M., \& Asteria, P. (2018). he Implementation of School Literacy Movement in Elementary School. In 1st International Conference on Education Innovation (ICEI 2017), 43-56. https://dx.doi.org/10.2991/icei-17.2018.12. 